\title{
4D BIM-ORIENTED DIGITAL PROJECT CONSTRUCTION MANAGEMENT FOR THE AEC INDUSTRY
}

\author{
SOFIA AGOSTINELLI, FRANCESCO RUPERTO \& ADRIANA SCARLET SFERRA \\ Department of Planning Design and Technology of Architecture, Sapienza University of Rome, Italy
}

\begin{abstract}
Project management is a working method that covers the entire life cycle of the project, from conception to planning, from design to construction, monitoring and post-construction activities. This approach allows to carry out project activities in relation to the agreed time and budget, to optimize the resources available and give immediate responses to unforeseen events while reducing inefficiencies and waste. The uniqueness of each project makes its management multifaceted, without prejudice to the validity of organizational principles, operational tools and, above all, the importance of a structured methodological approach. The uniqueness of a project also refers not only to its typological-functional, structural and architectural characteristics, as well as to the context of inclusion, but may also vary depending on the country and structure of commissioning. From time to time, the way in which the project is contracted and its characteristics can influence the design of the project from the earliest stages of setting up, and can change not only the responsibilities of the professionals involved, but also the application of managerial techniques. Such context and project complexities can find in the ICT technologies oriented to BIM a significant support to the enhancement of the activities of the project manager, being able to amplify the quality of the results and increase the level of control and monitoring of the project in the temporal (4D) and economic (5D) aspects. The contribution critically examines the opportunities of such a definable digital project construction management using real case studies and research, in which visual construction management has contributed to the creation of value in terms of reducing errors in the planning of the work and reducing process inefficiencies and waste of resources in a perspective of lean management.
\end{abstract}

Keywords: 4D, project management, construction management, digital construction, visual design construction.

\section{INTRODUCTION}

The possibility of building a digital environment oriented to the fourth dimension for time management, contributes to the development of construction processes that can minimize the waste of materials, time and resources, in order to generate the maximum possible economic value, meeting the requirements of customers. The efficient communication between the project stakeholders and the integrated transfer of information relating to the construction, in fact, also represents an advantage in terms of profit for the construction company [1]. In other words, 4D modeling can be a decisive support to the functions of risk management and construction planning.

\section{DEFINITIONS AND STATE OF THE ART}

The Computer Integrated Construction Research Group of the American University Penn State, codifies the use of the BIM oriented to 4D modeling in the phase planning, describing it as a process in which, implementing the model with the temporal dimension, it is possible to efficiently plan the realization of a work, and declines the main advantages.

4D modeling is configured as a powerful visualization and communication tool, which allows stakeholders to accurately monitor the flow of information, effectively managing the planning aspects; one of the main advantages of using a BIM approach oriented to $4 \mathrm{D}$, is the ability to improve and facilitate planning, as well as to express the spatial complexity of project management aspects related to planning and supporting further and subsequent 
analysis; integrating the management of human, equipment and material resources with the elements of the model, we also identify the relationships between the activities and the critical path; the functionality of a 4D model is then realized in the operational aspects of identification and resolution of spatial conflicts at the beginning of construction, optimizing the work scheduling, the sequencing of phases and solving any problems of interference; finally, a proper planning of the process also has a positive impact on the environmental aspects of a realization, but optimizing the management and monitoring of materials supplying on site, increases productivity with a consequent reduction of waste.

Technological innovation is gradually allowing new quality standards to be reached, but this always makes it necessary for professionals to have specific experience in each of the many specialisations of which it is composed [2].

In this regard, the Penn State University study also investigates the specific software resources and skills needed for $4 \mathrm{D}$, identifying as essential not only the knowledge of the specific 3D modeling tools, but especially the ways in which they can act as a support for the programming of construction processes [3].

Another important contribution to the development of knowledge and potential of BIM is the BIMe initiative, which is configured as a network of experiences and declinations on the subject, as well as a sharing effort undertaken by researchers and volunteers from both industry and academia. The BIMe initiative provides a research-based alternative to prescriptive top-down BIM deployment policies, offering an innovative, consistent and timely response to the opportunities and challenges brought about by the adoption of BIM at all organizational scales, through an integrated methodology and modular language for performance evaluation, and process optimization.

As a first declination, by identifying Model Uses, the information requirements linkedincorporated within the digital Models are identified and grouped, thus developing a broader modular language that links these requirements to system units, defined roles and competency items.

First, model uses are defined as a type of information uses that also includes aspects related to the use of data and documents. Model uses are divided into three categories:

Category I General Model Uses: The general uses of the model are applicable to all sectors, information systems and knowledge domains; including the word "modeling" in their name, they are generally measured using principles such as the level of definition or development. Examples of general model uses are: architectural modelling, conservation modelling, HVAC systems modelling, etc.

Category II Domain Model Uses: Uses are industry-specific, in particular construction uses identifies: capturing and representing, planning and designing, simulating and quantifying, monitoring and controlling, etc.

Category III Custom Model Uses: The "customized" uses of the model are a combination of the first and second category as they are tailored to each project, customer, client or specific modeling requirement. (e.g. the scope of application of a custom model use can be the modeling of security systems for a tourist accommodation).

This specific articulation of uses of the model can be exploited and applied in different areas, simplifying for example the identification of information requirements within the project protocols, facilitating the configuration of organizations, the assessment of the supply chain and the programming of project activities [4].

In the specific context of domain model uses, $4 \mathrm{D}$ characterization is identified in the planning and designing, simulating and quantifying and constructing and fabricating sectors. 


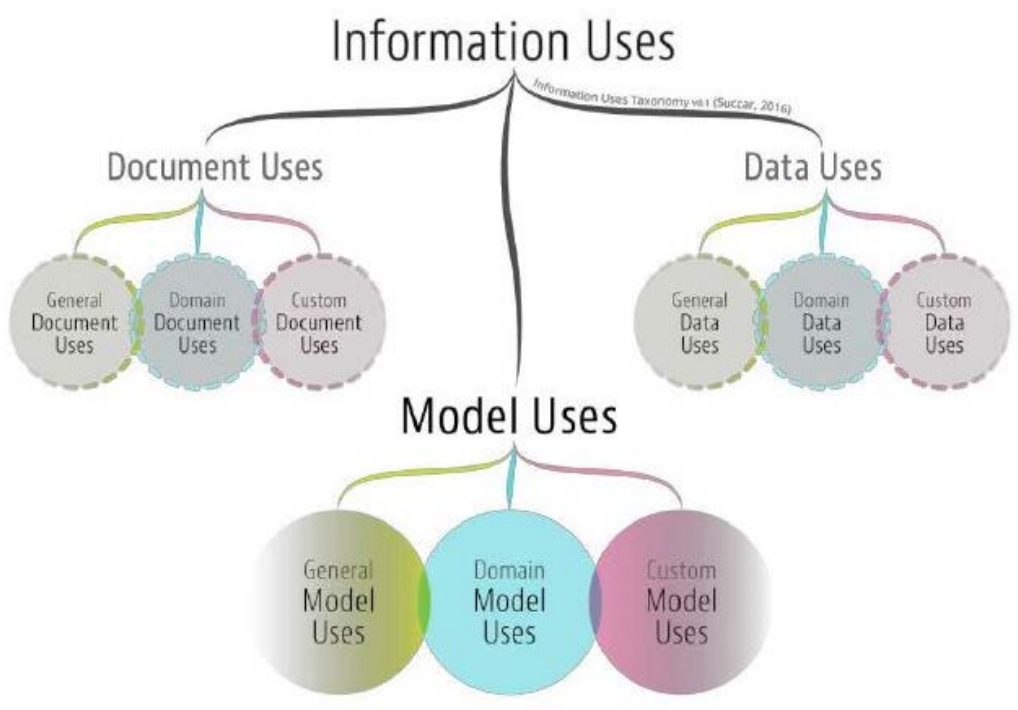

Figure 1: Information uses: BIMe.

In fact, modelling represents the starting tool for planning and designing the working phases, it allows to quantify in a unique way the project elements, simulating their installation, managing the construction phases and monitoring the aspects related to the technical, economic and temporal feasibility of the intervention.

In the specific case of management activities, the project manager identifies the methods for implementing the project, with particular regard to the forecast of time, cost estimates and the quality of the finished "product". It is a question of organically programming all the functions, variables and entities of the project, (i.e. foreseeing its development in such a way as to optimise time, the use of human and material resources and the costs to be incurred).

The optimization of the result is therefore a function of the best combination of these three variables: time, resources, costs, together with quality [5].

Programming times therefore means proceeding with the management of everything planned, using appropriate models and tools, pursuing the objectives to be achieved, and providing at the same time for monitoring and operational control.

It should also be noted that, while time, costs and the use of resources are always revisable and/or optimized with corrective actions, it will never be possible to easily re-intervene on the quality, unless a considerable increase in the estimated costs.

However, a correct planning is understood as the creation of a method that passes through the best possible knowledge of the objectives to be pursued, and its programming is understood as the activity aimed at optimizing, controlling and managing the phases of realization.

In technical practice, it operates through the PBS (project or product breakdown structure) tool, which is the first step in the hierarchical structuring of a project that disarticulates its sub-systems and detailed components, acting as an input to the WBS (work breakdown structure), which instead represents the destructuring of the "work" at subsequent levels and hierarchically connected phases; WBS defines in an orderly manner the sequences of the planned works and reaches the specification of their elementary activities, for which all the related quantities can be defined [6]. 


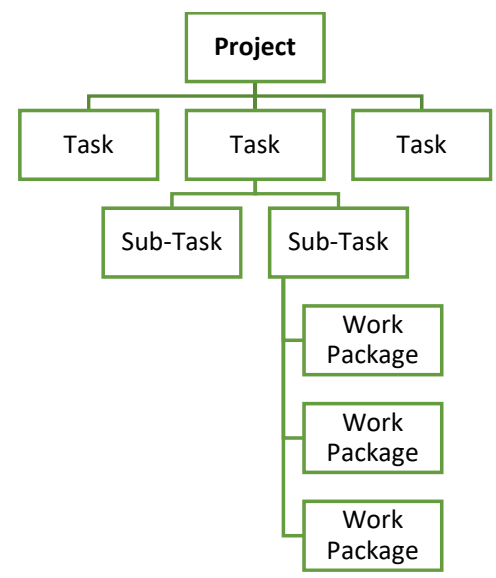

Figure 2: Structure of a PBS.

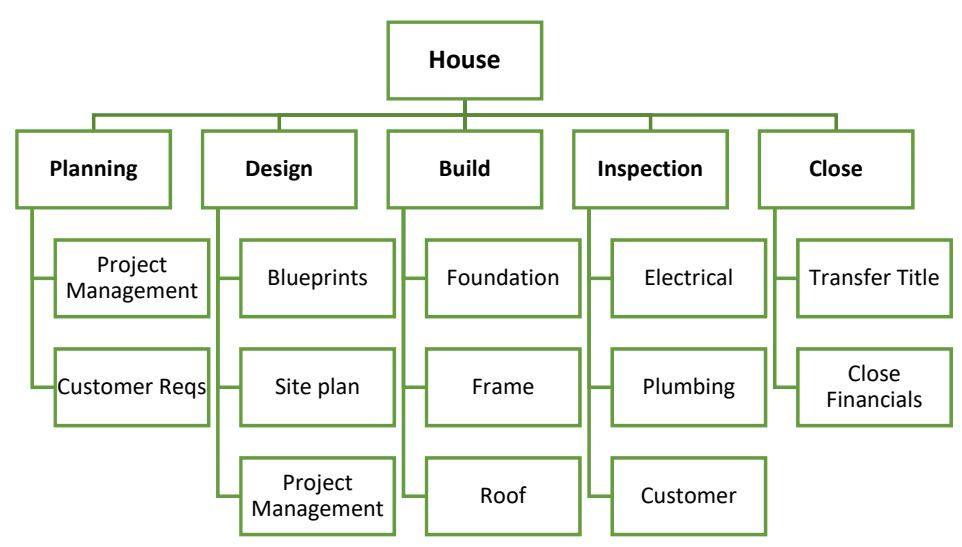

Figure 3: Structure of a WBS.

Moreover, the risk factor and its management represent an essential component in the planning and scheduling approach, since its unpredictability can affect the operational choices made in project management and therefore influence the main factors of attention (time, costs and resources).

Through careful planning, a detailed knowledge of all the general and particular conditions and circumstances useful for the development of the project is obtained. Therefore, in this phase risks assessment and management avoids the need to resort to corrective actions that have not been evaluated or budgeted for.

It is therefore essential to identify the risk and its analysis both qualitative and quantitative evaluation aimed at identifying the strategies to be implemented in order to reduce it, conducting constant monitoring and control, and setting thresholds of attention, as well as using values of a probabilistic nature and considerations on the impacts generated by the risk 
with a view to open-sharing of information and collaboration between the actors in the process [7].

Precisely in this sense, the quality and effectiveness of a digital information model to support project development guarantees solid control over the entities subject to the risks, as well as the homogeneous management of the information contained in it reduces the possibility of incurring in unforeseen circumstances and, at the same time, allows an effective application of any corrective actions.

The lack of possibility to have a solid and constant control on the project flow, managing consequently the possible risks, represents a limit for the traditional techniques of planning the work, because the project information is not managed and coordinated by providing for the integration of data, and this leads to an inevitable difficulty in controlling the planning tool and its outputs, also due to the absence of visual references.

The designer and/or expert company technician can also benefit from the higher levels of 4D control, combining the experience and individual capabilities with the potential of information communication technology in terms of computing power, information sharing, availability in mobile mode, and even taking advantage of the possibilities arising from the applications of augmented reality.

\section{TOWARDS A NEW SCENARIO}

Creating a 4D model means breaking down its construction phases in an environment where human resources, materials, equipment and spaces are connected to the planned activities, allowing easier verification of construction sequences, management of any variants and an immediate comparison between alternative scenarios [8]. The result is an efficient construction process, more reliable and secure than that managed with traditional techniques, capable of leading to savings of time and money, configuring a decision support system based on reliable information from the planning stage and always updated during construction.

By operating in $4 \mathrm{D}$, in fact, the planning of activities can be managed through the model and vice versa, and the possibility of having verification processes based also on the visualization of three-dimensional elements significantly increases the optimization of the temporal and economic aspects in the realization.

Through WBS you get an analytical breakdown of the construction into elementary parts, allowing you to organize the work through more-easily-manageable elements and breaking down the construction phase into components (such as subphases, activities and specific tasks), progressing with an increasing degree of detail, and following a top-down approach. This triggers a mechanism of articulation into increasingly smaller elements of WBE (work breakdown elements).

Only after the analysis of the WBS project, identifying the activities constituting the order, is it possible to elaborate the relative Gantt chart; estimating the effort of each activity in terms of man-hours necessary for its completion, defining the resources that will carry out each activity and calculating its effective duration, the man-hours are distributed over the assigned resources, considering the constraints present, defining the sequences between one activity and another, as well as the interdependencies and parallelism levels, placing these sequences in a work calendar and assigning precise starting and ending dates to each activity to calculate the duration of the project as a whole.

Through the analysis of a case study, the aim is to illustrate and verify how the BIM methodology can be adopted to achieve optimal management of the construction project, in particular by using 4D simulation environments as a support tool. 
Specifically, the project construction management phase was explored with the help of BIM-oriented workflows in order to plan and manage the activities of the construction of a new hospital complex in Kuwait, adjacent to an existing body and including:

- a main building of approximately $241,600 \mathrm{~m}^{2}$, with 3 towers, the highest of which has 18 floors;

- an annex building of approximately $49,206 \mathrm{~m}^{2}$, which houses the outpatient services, administrative offices and an auditorium;

- a multi-storey car park with 1,300 parking spaces: two-storey basement;

- three pedestrian walkways connecting the existing structure to the new buildings.

The total area involved in the project is $180,000 \mathrm{~m}^{2}$, with a built area of $351,000 \mathrm{~m}^{2}$ including services and parking. There will be 780 beds and is also planned an integrated environment with support areas.

The health centre, since it is located close to the beach, will be equipped with a sea barrier along the coast line for a total of $320 \mathrm{~m}$. Outside areas will be designed as well as parks and roof gardens.
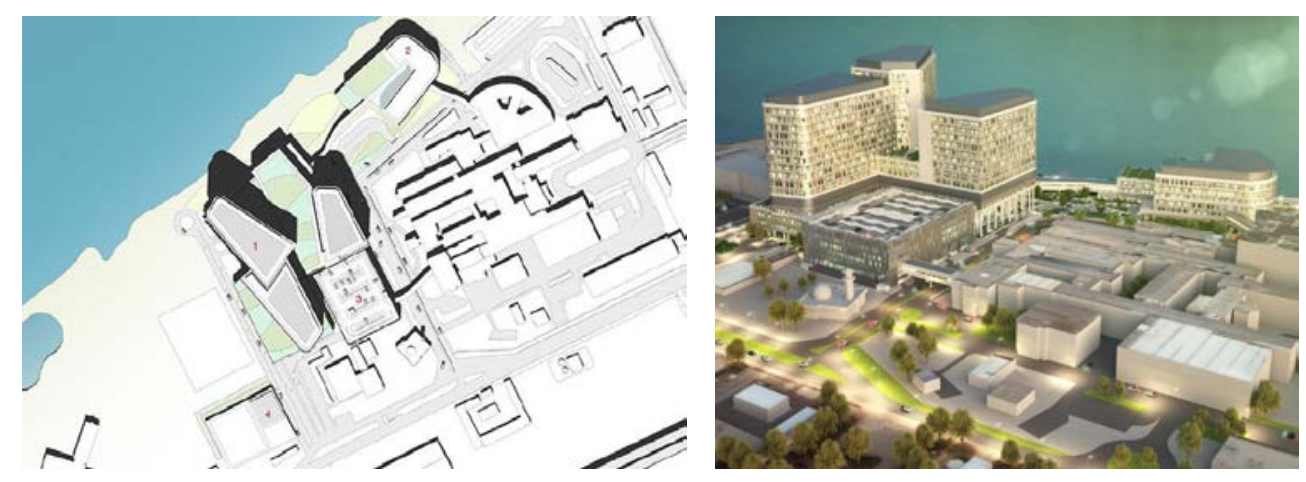

Figure 4: Project plan and render view.

The advantages of adopting a BIM process in the process management of a similar project can be immediately seen in the planning phase of the work, being able to identify and manage in a flexible way all the activities provided by the construction process. This flexibility derives precisely from the centrality of the BIM model, which allows you to control all the information relating to the work in a quick and precise way easily adaptable to the changing needs of the construction phase.

In fact, the traditional planning of the construction phases lacks the granularity and depth of details, as well as the possibility of exploring possible alternatives to the different construction sequences, such as to minimize the risks and program variations comparing different scenarios regarding the "strategy" of construction even in the early stages of planning, assessing their feasibility and efficiency, and obtaining a result in terms of optimal solution [9].

The first critical issue faced during activities was being able to exploit the incoming documentation (architectural and structural models, info-graphic elaborated) for the development of the fourth dimension, identifying the best operational strategy that would allow to optimize the potential of the models already realized. The modeling of the 4D structure was based on 3D models provided by the company. 
In the first instance, work planning led to the identification of three phases:

1. Definition of a workflow through the structuring of a WBS in order to define a guide in the identification and management of the activities that follow one another in the construction process in relation to the architectural and structural discipline, to which the activities have been associated.

2. Time planning of the construction phases, with the help of Synchro Pro software, which allowed to "automate" the BIM model to decline the relative 4D construction plan.

3. Planning of human and material resources necessary for the realization, through the elaboration of a metric calculation of materials and man-hours necessary for the process.

Using a 4D BIM approach, it is possible to manage the fourth dimension parametrically, equipping the single objects of the model with a specific temporal dimension, always taking into account the different variables involved, thanks to the continuous synchronization of the inputs inserted in the BIM model with the respective 4D structure, providing a clear visibility of the project data, facilitating and speeding up communication, and the analysis of the impact of any variants with respect to the entire realization [10].

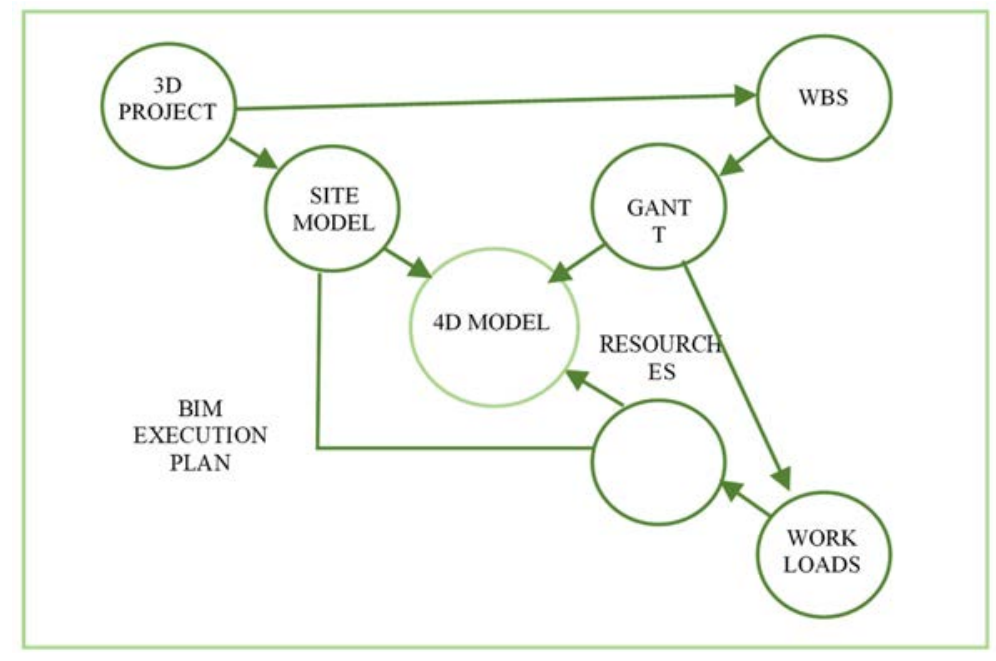

Figure 5: 4D Modeling flow.
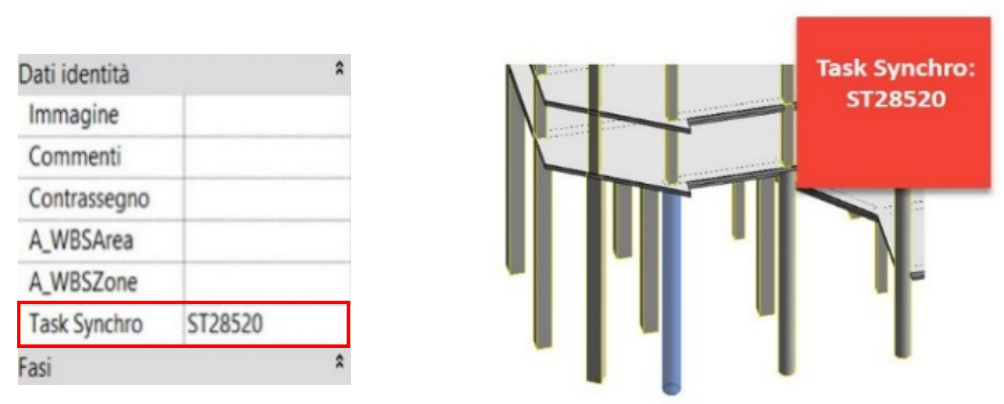

Figure 6: Task Synchro parameter use. 


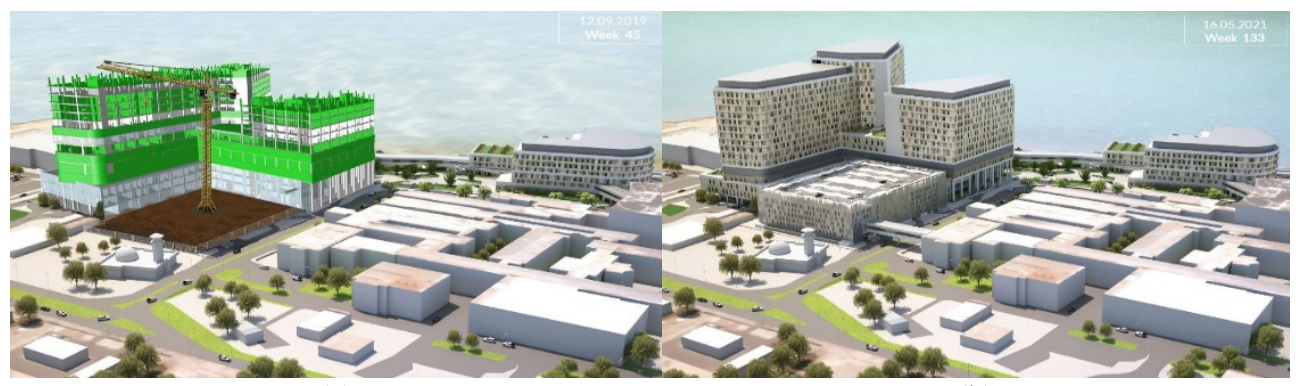

(a)

(b)

Figure 7: Simulation of progress. (a) Week 45; and (b) Week 133.

The 4D modeling has as a mandatory and essential phase called "auto-matching", a tool for assigning resources to activities based on the properties and attributes of both: having available the structural and architectural information models of the structure, it was possible to create a new group of shared parameters (e.g. "Task Synchro") to be assigned to all the objects of the models, using a specific code corresponding to the respective task of the Gantt chart made in Synchro Pro.

After importing the models complete with all their data and parameters into the 4D modeling software, performing auto-matching, connecting the objects to the activities planned by the Gantt, it can be performed the virtual simulation of the realization.

In this sense, the temporal simulation represents a clear practical confirmation of the planning activity carried out with the implementation of the fourth dimension, being a first real visual validator of the adequacy of the process.

Among the potentials of this level of development there is also the possibility of representing the construction site in a timely manner, taking into account all the conditions and critical points physically present in the area and existing prior to its settlement, as well as the urban context in which it is inserted [11]. By integrating the typological, quantitative and temporal information with that relating to the correct method of installation and/or the requirements relating to safety management, it is possible to carry out a specific "code checking", as well as a "clash detection", relating to the interference between workings and operating spaces [12].

In this way, always with the principle of the association of individual entities, aggregated in work activities and inserting information on their respective durations, we arrive at the creation of an information model capable of conducting visually and analytically the organization of the site, as well as the analysis and minimization of risks for workers.

By creating a model during the design phase, it is possible to carry out a quick check also on the work site, on the construction phases and on the construction costs estimates, promoting a better site logistics: in fact, the planners can manage the storage areas, the accesses, the positioning of the large equipment, the transports, etc., providing for the coordination of the supplies, coordinating the time and space for the loading/unloading on site, in order to obtain a better coordination of the works.

The added value of these 4D simulations therefore lies in the possibility of being used as tools for the detection of potential interference and information inconsistencies, and as a method to promote collaboration between the various professionals, providing a new tool for decision support to the project manager [13]. 


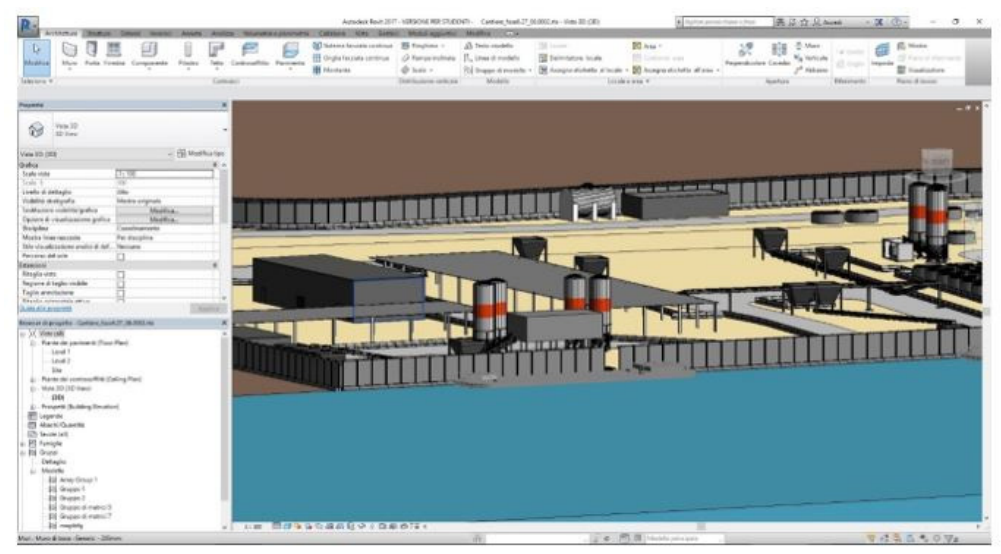

Figure 8: Revit model.

In this context, the simulation of the development of construction site activities in a 4D process is reported through a specific case study that has come up against the critical issues arising from the intention to move from a traditional workflow to an integrated one in the construction of a metro station; in particular, the phase of the construction considered is the "pre-construction", once the design phase that generated the construction project as an output has been completed, and following a call for tenders concluded with the entrusting of the construction phase to the company.

In the first instance, the necessary information about the project was collected, mainly related to programming, focusing the first analysis on the time sequence and focusing attention on a Gantt diagram already elaborated in the design phase [14].

Subsequently, the focus shifted to the site and its temporal evolution, having received the various layouts in .dwg format, divided by temporal phases and "transformed" into threedimensional information models through Revit, according to their subsequent placement in a 4D software.

Therefore, the above documents have been conveyed into the 4D modeling environment (Synchro Pro): the information model produced has been temporally connected to the Gantt diagram received, according to the site layout and its development.

Below is given a brief description of the site development:

- Phase 1: Site preparation;

- Phase 2: Excavation, preparation of cranes, equipment and storage areas;

- Phase 3: Preparation of a system of conveyor belts for disposal of the waste soil;

- Phase 4: Assembly of the TBM machine and construction of the tunnel excavation;

- Phase 5: Civil works for the construction of the metro station and finishes;

- Phase 6: Dismantling the construction site.

Once the time connections between the models and the Gantt diagram were completed, the so-called "3D path" was created, getting virtual paths to be executed by the machines, in order to simulate the construction site operations that occur at a particular stage of works.

In this phase, the 4D model can be considered completed and the next step is to create the project outputs: animations and snapshots that allow a clear spatial-temporal view of the of 


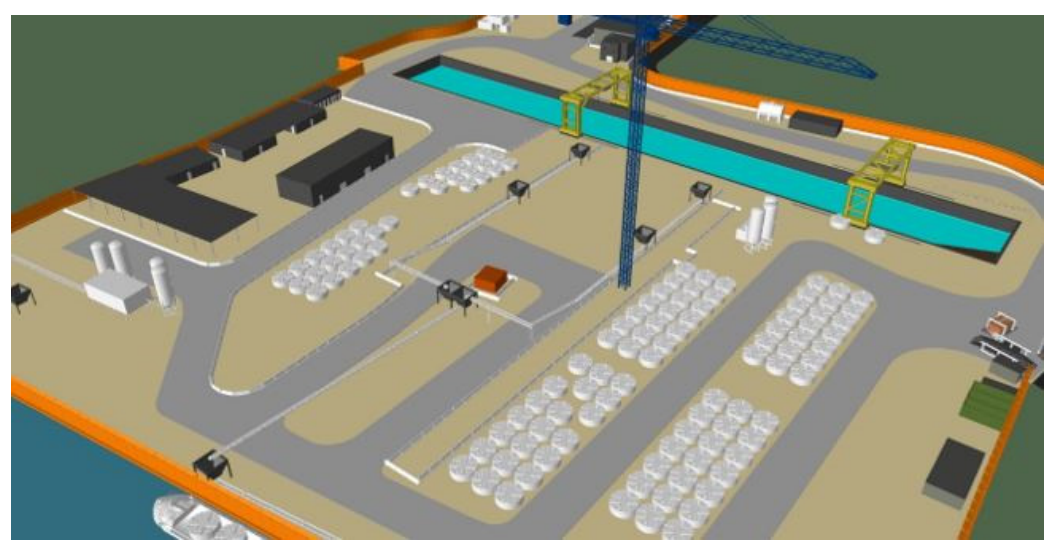

Figure 9: Overview of the construction site (start of works).

the site evolution, simulating the expected construction sequence, allowing the project team to assess any construction interference and any other problem related to site management and construction [15].

\section{CONCLUSIONS}

The use of BIM-oriented processes is increasingly changing the function of project managers, requiring greater data sharing and making this role crucial in terms of supervision and information management, focusing on collaboration, coordination and communication between stakeholders.

The advantages of this methodology are represented by a better collaboration among professionals, greater control of projects among stakeholders and a better overall quality that can be achieved; these benefits then translate into a reduction in time and costs. In particular, the concept of integration of the space/time binomial is placed in this context. Thanks to technological progress, it can be integrated with the three spatial dimensions, giving rise to 4D modeling processes, achieving the objectives of virtual design construction, intended as computerized simulation of the definition and development of a construction project. In fact, through the creation of virtual prototypes that allow you to visually analyze the project, it becomes possible to integrate teams and project strategies that until now have always been separated, also because of the existing technological limitations.

The creation of a built virtual model that can then be broken down and examined in depth, even in its different stages reduces the risks associated with the realization, simplifying the predictions of possible logistical/design conflicts, obtaining a more streamlined faster and less expensive process. In fact, the advantages are manifested both at an economic level (eliminating unnecessary costs), at a planning level (optimizing project activities), and at a constructive analysis level (identifying and correcting any errors before they occur during construction).

\section{ACKNOWLEDGEMENTS}

The authors would like to thank the following professionals for their contribution to this paper: Nicola Baraldi, Simone Belloni, Marzia Bolpagni, Filippo Daniele and Tom Dengenis. 


\section{REFERENCES}

[1] National Standards Institute, UNI 11337:2017: Construction and civil engineering works, Digital management of construction information processes, Milan, 2017.

[2] EUBIM Task Group, Handbook for the Introduction of Building Information Modelling by the European Public Sector. Strategic Action for Construction Sector Performance: Driving Value, Innovation and Growth, p. 78, 2017.

[3] Computer Integrated Construction Research Group at Penn State, BIM uses, 2013. www.bim.psu.edu/bim_uses/.

[4] BIMe, Model uses table. https://bimexcellence.org/wp-content/uploads/211in-ModelUses-Table.pdf. Accessed on: 20 Jul. 2019

[5] De Maria, C., Cumo, F. \& Sforzini, V., Project Management, la governance degli appalti, Esculapio, 2016.

[6] Project Management Institute, Guideline PMBoK (Project Management Body of Knowledge), 2017.

[7] Ferrara A. \& Feligioni E., BIM e Project Management, Dario Flaccovio editore, 2016.

[8] Valentini, S. \& Ruperto, F., BIM FM-Oriented, FMI Facility Management: Italy.

[9] Ruperto, F. \& Zacchei, V., Sezione BIM, Nuovissimo Manuale dell'Architetto, vol. 3, Mancosu Editore: Rome, 2019.

[10] Ciribini, A.L., BIM e digitalizzazione dell'ambiente costruito, Grafill, 2018.

[11] Russo Ermolli, S., The Changing Architect. Innovazione tecnologica e modellazione informativa per l'efficienza dei processi, Maggioli editore, pp. 31-77, 2018.

[12] Pavan, A., Mirarchi, C. \& Giani, M., BIM: Metodi e strumenti - Progettare, costruire e gestire nell'era digitale, Tecniche Nuove, 2018.

[13] Pagnotta, B., Digital Project Construction Management. Pianificazione delle fasi costruttive secondo i processi legati al BIM, Faculty of Architecture Degree Course in Project Management, 2019.

[14] Ruggero, S. \& Zuliani G., 4D Modeling: Sperimentazione di metodi e strumenti di gestione digitale dei processi costruttivi, Faculty of Architecture Degree Course in Project Management, 2017.

[15] Alesi, U., Aimetti, M., Melchini,T. \& Ruperto, F., BIM BANG. Breve introduzione all'era digitale del mondo delle costruzioni, National Council of Architects and Planners, 2019.

[16] Dawood, N. \& Mallasi, Z., Construction workplace planning: assignment and analysis utilizing 4D visualization technologies. Computer-aided Civil and Infrastructure Engineering, pp. 498-513, 2006.

[17] Jongeling, R., Kim, J., Fischer, M., Morgeous, C. \& Olofsson, T., A quantitative analysis of workflow, temporary structure usage, and productivity using 4D models. Automation in Construction, pp. 780-791, 2008. 